\title{
Pedagogical Assessment of General Professional COMPETENCIES OF TECHNICAL ENGINEERS TRAINING
}

\author{
Darina Barinova, Oleg Ipatov, Maria Odinokaya \& Valentin Zhigadlo
}

Peter the Great St. Petersburg Polytechnic University
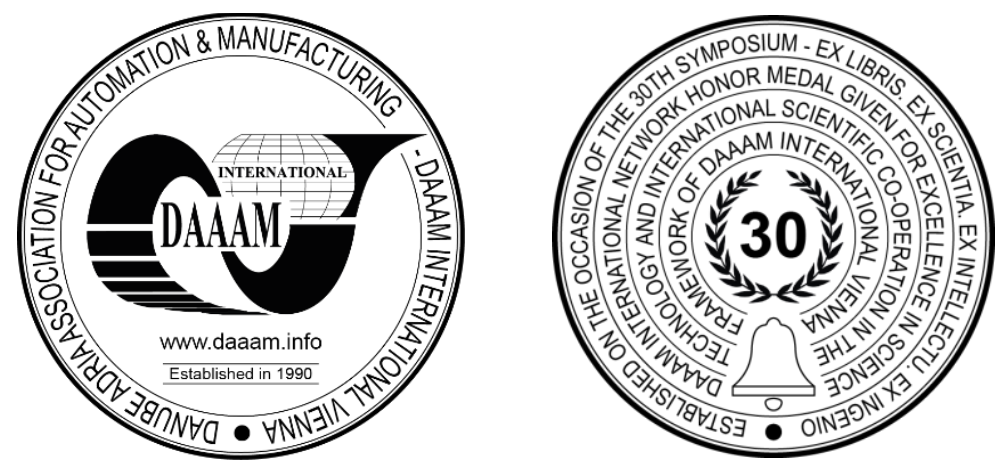

This Publication has to be referred as: Barinova, D[arina]; Ipatov, O[leg]; Odinokaya, M[aria] \& Zhigadlo, V[alentin] (2019). Pedagogical Assessment of General Professional Competencies of Technical Engineers Training, Proceedings of the 30th DAAAM International Symposium, pp.0508-0512, B. Katalinic (Ed.), Published by DAAAM International, ISBN 978-3-902734-22-8, ISSN 1726-9679, Vienna, Austria

DOI: $10.2507 / 30$ th.daaam.proceedings.068

\begin{abstract}
The article is devoted to the actual problem of pedagogical assessment of general professional competencies of technical engineers' students. The analysis of the results of a study conducted at Peter the Great St. Petersburg Polytechnic University is presented, the criteria and characteristics for evaluating general professional competencies at various stages of their formation in the educational process are identified, and the problem areas for evaluating students' academic achievements are revealed. Experimental work confirmed the effectiveness of the identified criteria and characteristics of assessing the competencies at various stages of their formation in the educational process, namely, conducting verification work; preparation of monologic utterance on one of the studied subjects; carrying out written work in accordance with the lesson plan; conducting home reading; preparation of project work; implementation of work on a distance course; conducting an intermediate; conducting a final test; the introduction of bonus points for attendance. In assessing the success of a technical university student, the subjective assessment of the teacher is also taken into account. This form of assessment can serve as a practical basis for the activities of technical universities, allowing qualitative and quantitative assessment of changes in the educational development of students of technical universities.
\end{abstract}

Keywords: competence-based approach; pedagogical diagnostics; information technology; engineering education; general professional competences.

\section{Introduction}

The socio-economic changes taking place in Russia demand to modernize the social sphere and, in particular, the education system connected with economic processes through the training process. One of the ways to improve the quality of future specialists training is the targeted formation of their competence, especially for engineers (competence-based approach) [1].

In connection with the introduction of a competence-based approach, it became obligatory to update the content, methodology and relevant learning environment, as well as the system for assessing students' knowledge at Russian universities. A method was also introduced for calculating the complexity of education as the calculation of academic 
credits. It is possible to use a set of criteria and characteristics for assessing competencies at various stages of their formation. Competence refers to the elementary (logically indivisible) resources of vital activity (professional activity), that is, the ability of a person to put his competence into the practice work [2].

Currently, an indicator of readiness for the professional activity of a future engineer is unified general professional competence, necessary for obtaining new knowledge and adapting existing knowledge to new requirements, as well as adapting to the changing situation of one's own professional growth and increasing one's own labour and economic mobility through training throughout life; general professional (invariant to professional activity), related to social, communicative, methodical and other competencies that are necessary for effective work in various professions and fields of activity; professional, related to professional activities. For graduates of higher education (undergraduate level), approved competencies include systemic and critical thinking (ability to search, critical analysis and synthesis of information, apply a systematic approach to solve problems), develop and implement projects ability to determine the range of tasks within the framework of the goals set and choose the best ways to solve them, based on the existing legal norms, available resources and restrictions), teamwork and leadership (ability to carry out social interaction and fulfil its role in a team), communication (ability to carry out business communication in verbal and written forms), intercultural interaction, self-organization and self-development (ability to manage their time, to build and implement the trajectory of self-development based on the principles of self-education throughout life (ability to maintain an adequate level of physical fitness to ensure full social and professional activities) [3].

The developed criteria for evaluating competences at various stages of their formation are one of the most important elements of the educational process in engineers training and can be presented in the form of several levels of their formation when studying a specific training course or academic discipline.

\section{Purpose}

The purpose of the study is to identify the criteria and characteristics of the evaluation of universal competencies at various stages of their formation in the educational process of engineers at Peter the Great St. Petersburg Polytechnic University.

\subsection{Materials and methods}

Every student faces a situation when it is necessary to determine the educational achievements he got. Thus the lecturer is the one who explains the points he had received at the end of the training course. A list of self-analysis of the learning productivity of each student can be formed, both for a specific training lesson and for the entire training period to assess the development of his universal competencies.

The main characteristic of the quality of any type of control is the objectivity of the teacher in assessing the results of students' learning activities. The assessment system must meet the criteria of systematicity and adequacy, the conformity of the assessment to the level of students' knowledge. The criteria for assessing the development of universal competencies of a teacher should be based on the combination of organizational, methodological methods of obtaining and analysing quantitative and qualitative indicators characterizing the effectiveness of the educational process.

Evaluation of engineers' students' academic achievements begins from the first weeks of their studies. A mandatory level for each bachelor student of an educational organization upon completion of their educational program is the "pass" level, which, according to the competence rating scale, corresponds to the minimum parameters and serves as an indicator of the competence formation. This level can be correlated with the rating of "satisfactory". If the student has not reached this level, then the competence is considered to be unformed and corresponds to an "unsatisfactory" assessment. The level of assuming that the minimum parameters for the formation of competence are exceeded is basic and corresponds to a "good" estimate of approximately $75 \%$. The advanced level assumes the characteristics of the formation of competencies for the student, which are the most demonstrated and constitute 94-100\%. Advanced level corresponds to the rating of "excellent."

\section{Research}

During the first week of education, it is important for the teacher to conduct pedagogical monitoring of the individual achievements of each student (the productivity of learning activities is a characteristic of individual achievements) by means of starting diagnostics, which checks the student's readiness to study at a technical university. In addition to the initial diagnosis, the teacher further conducts an intermediate and final control to track the dynamics of the students' individual achievements [4].

The initial pedagogical diagnostics in the first year of study is based on the results of monitoring the general readiness of students to study at a university and the results of an assessment of their readiness to study a course of study. The pedagogical diagnostics is a set of specially selected and systematized tasks, which allow: to determine the features of students' mastering of subject knowledge and skills; to identify the nature of the difficulties of the student and to establish their causes; establish the level of mastery of educational activities; assess changes in student learning achievements. The partial or even complete lack of individual skills of students, the scarcity and incompleteness of ideas, the low level of social development is not a basis for discriminatory decisions, but indicates the need for individual work with the student. 
Pedagogical diagnostics is carried out throughout the entire training course by a lecturer. The specific dates for conducting pedagogical diagnostics are determined by the directorate of the university, as well as by the lecturer himself. As a rule, initial pedagogical diagnostics of first-year students' readiness can be carried out in the second week of September of the year, then at each training lesson, throughout the entire course of study, and the pedagogical diagnosis is completed at the end of the training course. [5]

The method of conducting a diagnostic study is carried out as a group survey, during which students perform various learning tasks. After analysing the results, an individual conversation is conducted with individual students, refining the results obtained, finding out the reasons for the mistakes made. Pedagogical diagnostics in the first year differs from all subsequent ones when the lecturer provides students with the detailed explanations of their performance and also provides them with instructions on how to complete the assignments. Students can proceed to the next academic assignment only when they have basically completed the previous one. The total duration of the group diagnostic examination depends on what kind of training task the students perform, and can last from 7-15 minutes to 1 hour and 30 minutes. After monitoring an individual student card is compiled (his profile). If a student has scored the lowest number of points, the lecturer thinks over the work plan with this student and offers his individual route.

The system of evaluation of student's educational achievements during the semester is carried out through a variety of pedagogical monitoring tools. Let us consider in more detail the procedure for applying monitoring the evaluation of students 'academic achievements for engineers. In order to create a natural learning situation, the lecturer conducts observations at the training session. In the process of observation following points are recorded: the interest of students during educational and extracurricular activities (stable, situational, indifferent attitude to educational tasks); the quality side of the actions performed and their character (impulsivity of performance, slowness, tension, alignment of the algorithm of one's own activity, correctness of execution); student's reaction in a situation of difficulty, failure (termination of activities, acceptance (refusal) of assistance, the implementation of a number of additional trial-actions); reflection and correction of one's own activities (the ability to correlate the obtained educational results with the tasks set, evaluate the achieved result, the ability to see and correct the mistake).

Assessment of the level of formation of general professional competence involves the achievement of several stages, and is carried out in the form of intermediate certification, in particular, in the form of tests, the final exam and is determined by points, translated into assessments. According to the results of the exam, a differentiated grade is given on a four-point scale: "excellent", "good", "satisfactory", "unsatisfactory".

The student needs to receive a positive assessment for each type of work, such as test work (usually in the form of a test for the implementation of the current test of the correctness of students learning the teaching materials) after each training session, a monologue statement on one of the studied training topics, written work in accordance with with a lesson plan, home reading, project work, distance course work, intermediate (inter-semester test), final test, teacher's subjective assessment, as well as through introducing bonus points for attendance [6].

The advantage of carrying out the current verification work in the classroom is that in a few minutes you can get a slice of knowledge of bachelor students. Approximate criteria for evaluating educational tasks may be as follows: 0-59\% - "unsatisfactory" - 0 points, 60-74\% - "satisfactory" - 3 points, 75-89\% - "good" - 4 points, 90-100\% - "Excellent" - 5 points. Students perform study tasks that can be distributed according to the degree of uniqueness of the resulting product of their educational activities: note-taking; preparation of the report, presentation; writing their own essays, independent search for educational materials and analytical work with them on a given educational topic; performing a home reading test. The task of current control is to determine the degree of achievement of the set local learning goals: mastering educational material on individual topics or sections; timely detection of gaps in the preparation of students and the adoption of necessary measures to improve the teaching methodology of the academic discipline; organization of students' activities during the training session [7], [8].

\section{The criteria}

The criteria for evaluating the tasks are as follows:

- test after each lesson: $90-100 \%$ - excellent - 5 points $75-89 \%$ - good - 4 points $60-74 \%$ - satisfactory - 3 points 0 $59 \%$ - unsatisfactory - 0 points (the student needs score 5 points for each test of 4 , that is, 20 points);

- monologic statement: excellent - 10 points good - 8 points satisfactory - 6 points unsatisfactory - 0 points; content of the utterance - 2 points, organization of the statement (structure, consistency) - 2 points, vocabulary (use of the learned vocabulary on the topic) - 2 points, grammar - 2 points, pronunciation - 2 points (the student needs to score 10 points);

- written work: excellent - 10 points, good - 8 points, satisfactory - 6 points, unsatisfactory - 0 points; content - 2 points, organization of the text (structure, consistency) - 2 points, vocabulary (using the learned vocabulary on the topic, means of logical communication) - 2 points, grammar - 2 points, spelling, punctuation - 2 points (the student needs to score 10 points) ;

- home reading: excellent - 14 points good - 12 points satisfactory - 9 points unsatisfactory - 0 points (the student needs to score 14 points, that is, 4 points for the test and 10 points for retelling);

- project work: excellent - 15 points good - 12 points satisfactory - 9 points unsatisfactory - 0 points (the student needs to score 15 points);

- work on a distance learning course: $90-100 \%$ - 5 points, $75-89 \%$ - 4 points, $60-74 \%$ - 3 points, $0-59 \%$ - 0 points (the student needs to score 5 points); 
- intermediate test: $90-100 \%$ - excellent - 10 points, $75-89 \%$ - good - 8 points, $60-74 \%$ - satisfactory - 6 points, $0-59 \%$ - unsatisfactory - 0 points (the student needs to score 10 points) ;

- final test: $90-100 \%$ - excellent - 10 points $75-89 \%$ - good - 8 points $60-74 \%$ - satisfactory - 6 points $0-59 \%$ unsatisfactory - 0 points (the student needs to score 10 points).

To qualify for the semester, you must score at least 60 points (60\% of 100 points).

Intermediate attestation is carried out at the end of each month (as a rule, around the 25th of the month) and determines the formation of competence of students in the process of studying their academic discipline. Intermediate certification is carried out in order to determine the degree of achievement of the goal of training for this training course.

Also, the lecturer analyses the student lecture notes, certification journals, which are used to determine the progress of students participating in the educational process [9], [10]. During the study of student lecture notes, the teacher can trace the quality of the performance of homework, which may differ significantly from work in the classroom. Homework can be done more accurately with fewer errors and corrections. This fact indicates that external stimulation in the performance of homework by the lecturer contributes to improving the quality of work performed, motivating learning activities.

The final control is carried out at the end of the semester. There are pass-fail tests which demonstrate the pass level of competence formation. Projects are also rated by the mark: "pass", "fail". Such projects are rated on a four-point scale: "excellent", "good", "satisfactory", "unsatisfactory", as well as the final examinations. The system of evaluating students' academic achievements is recognized and becomes a significant and powerful tool for productive work, both for the lecturer and the students themselves, allows not only to be convinced of mastering the educational material, but also shows a deeper disclosure of the dependencies between the educational tasks making this work personally meaningful.

\section{Experimental research results}

The study was conducted in two stages. At the first stage (spring semester of the 2017-2018 year), the criteria for assessing the universal competencies of engineers' students at the Higher School of Education and Management of the St. Petersburg Polytechnic University of Peter the Great were identified. Conclusions about the quality of students' readiness for further educational activities were carried out on the basis of the analysis of the results of work during the year and an interview with the Directorate of the Higher School of Education and Humanities, within the framework of the protection of individual plans. At the second stage (the fall semester of the $2018-2019$ year), the problems of assessing the universal competencies of the students were identified. The results of the study were based on the analysis of data obtained in the course of pedagogical diagnostics.

Experimental research base. In the first part of the study, first-year students took part in the research (27 students). According to the results of the analysis of their educational activities during the year, the level of their readiness for professional activity was evaluated, and an initial assessment of students' universal competencies was carried out. The second stage was held with the participation of the same training group. During the second stage, the relationship between the assessment of students' universal competencies and their personal qualities was revealed.

Research methods: First stage: A study conducted in the spring semester of the 2017-2018 year revealed the criteria for assessing the universal competencies of engineers' students.

Stage Two: A study conducted in the fall semester of the 2018-2019 year was based on the results of a survey on the assessment of students' universal competencies. In addition to the survey, the Directorate conducted an individual interview with the lecturer, which included questions aimed at identifying: personal opinion about the student's success, readiness to complete educational tasks in the proper amount. As part of the study, an attempt was made to assess how clearly the undergraduate students were aware of their areas of responsibility and timeframes that must be met in order to complete their learning tasks successfully.

The analysis of the educational activities of engineers students and the evaluation of their universal competences was carried out on the basis of an assessment of the following parameters: the volume of completion of educational tasks; the absence (presence) of disciplinary sanctions and violations of discipline; data on the academic performance of educational groups in comparison with similar groups, students of one department; the absence (presence) of shortcomings and the untimely fulfilment of educational tasks; adherence to professional etiquette; positive results of attendance of studies.

Data analysis: At the first stage of the study, the level of readiness of students for learning activities was identified. $80 \%$ of respondents passed the initial test satisfactorily. The level of their readiness to carry out professional activities was rated as: high $(0 \%)$, medium $(80 \%)$ and low $(20 \%)$. At the second stage, through questioning and interviewing, it was possible to identify the following problems: an increase in the volume of educational tasks; students' uncertainty in the implementation of educational tasks; lack of understanding of the quality of documentation (notes, registration of educational work); wrong mode of work and rest; experiences associated with the need to demonstrate their capabilities; misunderstanding of the purpose of evaluating educational achievements; weak motivation for learning, self-development and self-improvement, due to limited amount of time.

\section{Conclusion}

The increase in the number of bachelor students in study groups, the need for ongoing monitoring of knowledge, as well as the general tendency to reduce the subjectivity of assessment by a specific lecturer led to the spread of various 
types of monitoring the results of the formation of universal competencies. The main purpose of their assessment is to promote cognitive activity and motivation to study the educational material of the module or program as a whole. Assessment of the level of formation of universal competencies is directly related to the strategy of monitoring learning outcomes. Methods of control play a significant role in the organization of the activity of a lecturer and a engineer's student. Carrying out pedagogical diagnostics makes it possible to reveal the general readiness of students to study at a Russian technical university. The revealed criteria and characteristics of evaluation of universal competencies at various stages of their formation in the educational process, presented in the analysis of the results of a study conducted at the St. Petersburg Polytechnic University of Peter the Great, help to focus the efforts of the lecturer on the correction of deficiencies identified in the learning process.

The problem of pedagogical evaluation of the universal competencies of engineering students is currently not receiving enough attention. The presented analysis of the research results allows to identify the criteria and characteristics of the evaluation of universal competencies at various stages of their formation in the educational process, as well as to reveal the problem areas for assessing students' academic achievements. The carried out experimental work confirmed the effectiveness of the identified criteria and characteristics of the assessment of students' competences at various stages of their formation in the educational process. This form of assessment can serve as a practical basis for the activities of universities in the educational process of students in various specialties, allowing qualitative and quantitative assessment of changes occurring in the educational development of students.

Furthermore, we consider this approach to be recognized and become a significant tool for productive work, both for the lecturer and the students themselves, which also allows to reveal strong dependencies between the educational tasks performed and makes this work personally meaningful.

The experience of teaching humanities in the preparation of engineers shows that mastering educational material is more effective if the study of relevant sections of the academic discipline is accompanied by the solution of applied problems, the themes of which correspond to the direction of study. Such an approach to the formation of humanitarian education allows students to see and understand the relationship between the humanities and engineering disciplines and gives reason to expect success in this direction.

The next step is to spread this experience for other disciplines in the St. Petersburg Polytechnic University of Peter the Great.

\section{References}

[1] Litchfield, K., Javernick W. (2016) Technical and Professional Skills of Engineers Involved and Not Involved in Engineering Service. Journal of Engineering Education. Vol. 105 Issue 1, p70-92. 23p.

[2] Almazova, N \& Barinova, D \& Ipatov, O (2018). Forming of Information Culture With Tools of Electronic Didactic Materials, Proceedings of the 29th DAAAM International Symposium, pp.0587-0593, B. Katalinic (Ed.), Published by DAAAM International, ISBN 978-3-902734-20-4, ISSN 1726-9679, Vienna, Austria DOI: 10.2507/29th.daaam.proceedings.085.

[3] Rubtsova A., Almazova N. (2019) Productive Model of Foreign Languages Learning: Realities and Prospects. Advances in Social Science, Education and Humanities Research, volume 289. International Conference on Communicative Strategies of Information Society (CSIS 2018) https://www.atlantis-press.com/proceedings/csis18/55913842 (accessed on 25 February 2019).

[4] Khomchenko, V. K., Gebel, E. S., \& Peshko, M. S. (2018). Educational robotics as part of the International Science and Education Project "Synergy" in realizing the social needs of society on the road to the Industrial Revolution “Industry 4.0." EAI Endorsed Transactions on Energy Web, 5(16), 153816. doi:10.4108/eai.30-1-2018.153816

[5] Yerofeyev S., Ipatov O., Markov S., Potekhin V., Sulerova A., Shkodyrev V. (2016). Adaptive Intelligent Manufacturing Control Systems, Proceedings of the 26th DAAAM International Symposium, pp.1016-1024, B. Katalinic (Ed.),PublishedbyDAAAMInternational,ISBN978-3-902734-07-5,ISSN1726-9679,Vienna,Austria.

[6] Razinkina, E., Pankova, L., Trostinskaya, I., Pozdeeva, E., Evseeva, L., Tanova, A. (2018). Student satisfaction as an element of education quality monitoring in innovative higher education institution // E3S Web of Conferences, Volume 33, 03043 (2018). https://doi.org/10.1051/e3sconf/20183303043

[7] Kogan, M.S., Khalyapina, L.P., Popova, N.V. (2017). Professionally-oriented content and language integrated learning (CLIL) course in higher education perspective // ICERI 2017 Proceedings: 10th International Conference of Education, Research and Innovation. 16th-18th November, Seville, SPAIN, pp. 1103-1112

[8] Zhigadlo, V.E., Odinokaya, M.A. (2017). Using the technology of educational podcasts for teaching Hindi in a technical university as a means of improving the quality of additional numeracy education. Language and Culture, 38, 207-226. doi: 10.17223/19996195/38/14.

[9] Bolotin, A.E., Piskun, O.E., \& Pogodin, S.N. (2017). Special features of sports management for university students with regard to their value-motivational orientation, Theory and Practice of Physical Culture. No 3. pp. 51-53.

[10] Zakharova I. (2016). The project "Our Universities" in the framework of strategic partnership between Peter The Great St. Petersburg Polytechnic University (Russia) and Leibniz University Hannover (Germany)// Sharing practices - this my story, what is yours: International week 10-14.10.2016 Saimaa UAS Series A: Reports and Studies 68 1797-7266 http://www.theseus.fi/bitstream/handle/10024/115888/KV\%20viikk 